\title{
PROPAGAÇÃO DE GABIROBEIRAS VIA ESTAQUiA ASSOCIADA AO ÁCIDO INDOLBUTÍRICO ${ }^{1}$
}

\author{
Laísse Danielle Pereira², Maraíza Lima Costa ${ }^{3}$, Jefferson Fernando Naves Pinto ${ }^{4}$, Hildeu Ferreira da \\ Assunção ${ }^{5}$, Edésio Fialho dos Reis ${ }^{5}$, Danielle Fabíola Pereira da Silva ${ }^{5}$
}

\begin{abstract}
RESUMO - Uma das ameaças ao cerrado é a exploração de certas espécies nativas, que tem sido feita de forma extrativista e muitas vezes predatória, tornando-se imprescindíveis ações no sentido de se fazer o cultivo e domesticação destas espécies. Dentre as inúmeras frutíferas nativas que possuem alto potencial para exploração comercial, destaca-se a gabirobeira, que se encontra sob forte pressão devido ao impacto causado pela fragmentação das suas populações, seja pelo extrativismo inadequado, ou pela expansão das fronteiras agrícolas. O objetivo deste trabalho foi avaliar o uso de ácido indolbutírico na sobrevivência, brotação e enraizamento de estacas de gabirobeira. Foram coletadas estacas lenhosas de gabirobeiras da coleção do banco de germoplasma de Campomanesia spp. da UFG-Regional Jataí. Utilizaram-se estacas das espécies Campomanesia adamantium e Campomanesia pubescens segmentadas em ramos de $15 \mathrm{~cm}$ de comprimento contendo um par de folhas narte apical e selecionadas as estacas que apresentavam diâmetro médio de 2,8 $6 \pm 1,29 \mathrm{~cm}$. O experimento foi conduzido em delineamento inteiramente casualizado para cada espécie em estudo com 5 tratamentos e 4 repetições com 8 estacas/parcela. Os tratamentos foram compostos por 0, 800, 1600, 2400 e $3200 \mathrm{mg} / \mathrm{L}$ de Ácido indolbutírico (AIB). As estacas foram tratadas nas doses de Ácido indolbutírico (AIB), com 15 segundos de imersão. Após tratamento com AIB as estacas foram plantadas em bandejas de isopor com as bases perfuradas contendo como substrato areia lavada. Durante todo o período experimental foi utilizado o sistema de nebulização intermitente. Sessenta dias após a instalação do experimento as estacas foram avaliadas, quanto a Brotação, sobrevivência das estacas, porcentagem de enraizamento e porcentagem de calejamento. O uso de AIB em estacas de gabirobeiras proporcionou maior percentagem de brotação bem como maior sobrevivência das estacas, porém não proveu enraizamento.
\end{abstract}

Palavras-chave: Campomanesia adamantium, Campomanesia pubescens, cerrado, fruteira nativa, propagação.

\section{GABIROBEIRAS PROPAGATION BY CUTTING THE ASSOCIATED INDOLBUTYRIC ACID}

\begin{abstract}
One of the threats to the cerrado is the use of certain native species, which has been made of extraction and often predatory, making it essential actions to make the cultivation and domestication of these species. Among the numerous native fruits that have high potential for commercial exploitation, there is the gabirobeira, which is under strong pressure due to the impact of the fragmentation of their populations, either by inadequate extraction, or the expansion of the agricultural frontier. The objective of this study was to evaluate the use of Indolbutyric acid (IBA) in survival, sprouting and rooting gabirobeira
\end{abstract}

\footnotetext{
1 Trabalho desenvolvido com apoio da CAPES, CNPq e FAPEG.

${ }^{2}$ Mestranda no Programa de Pós-Graduação em Agronomia -Universidade Federal de Goiás - UFG Regional Jataí - Campus Jatobá - Rodovia BR 364, Km 192, Parque Industrial, n. 3800 CEP 75801-615, Jataí -Goiás - Brasil. laissedaniellep@ gmail.com

${ }^{3}$ Acadêmica em Agronomia - Universidade Federal de Goiás - UFG Regional Jataí - Campus Jatobá - Rodovia BR 364, Km 192, Parque Industrial, n. 3800 CEP 75801-615, Goiás - Brasil. maraiza-15@ hotmail.com

${ }^{4}$ Biológo-Universidade Federal de Goiás - UFG Regional Jataí - Campus Jatobá - Rodovia BR 364, Km 192, Parque Industrial, n. 3800 CEP 75801-615, Jataí -Goiás - Brasil.jeffnaves@ gmail.com

${ }^{5}$ Professores-Universidade Federal de Goiás - UFG Regional Jataí - Campus Jatobá - Rodovia BR 364, Km 192, Parque Industrial, n. 3800 CEP 75801-615, Jataí -Goiás - Brasil. hildeu@ufg.br, edesiofr7@gmail.com, daniellefpsilva@gmail.com
} 
stakes. Hardwood cuttings were collected from gabirobeiras the collection of germplasm bank of Campomanesia spp. UFG-Regional Jataí. Were used cuttings species Campomanesia adamantium and Campomanesia pubescens segmented into branches $15 \mathrm{~cm}$ long containing a pair of sheets selected in the apical part and the cuttings had average diameter of $2.86 \mathrm{~cm} \pm 1.29$. The experiment was conducted in a completely randomized design for each species under study with 5 treatments and 4 repetitions with 8 cuttings/portion. The treatments were $0,800,1600,2400$ and $3200 \mathrm{mg} / \mathrm{L}$ of IBA. The cuttings were treated at doses of $A I B$, with 15 seconds of immersion. After treatment with AIB the cuttings were planted in trays with perforated bases containing as substrate washed sand. Throughout the trial period it was used intermittent misting system. Sixty days after the installation of the experiment the cuttings were evaluated for the Sprouting, survival of the cuttings, rooting percentage and percentage of callus formation. The use of IBA in gabirobeiras rooting provided larger percentage of sprouting as well as higher cutting survival, but did not provide rooting.

Keywords: Brazilian savanah, Campomanesia adamantium, Campomanesia pubescens, native fruit tree, propagation.

\section{INTRODUÇÃO}

Com a aprovação do novo Código Florestal pela Lei $\mathrm{n}^{\circ} 12.651$, de 25 de maio de 2012 e a possibilidade de manejo sustentável das áreas de preservação permanentes e reservas legais, o plantio de espécies frutíferas nativas tem se tornado uma opção viável, com perspectivas de manutenção das espécies de interesse, melhoria da qualidade alimentar e geração de emprego e renda, principalmente para o agricultor familiar (Brasil, 2012).

A seleção de plantas matrizes na natureza ou em coleções e a propagação vegetativa daquelas mais promissoras, obtendo, assim, clones que poderão ser cultivados comercialmente, poderá ser a primeira medida para introdução de frutíferas nativas, o que está de acordo com a nova legislação sobre manejo e preservação da biodiversidade (Brasil, 2015).

Dentro das diversas espécies nativas passíveis de introdução ao cultivo, a gabirobeira ocupa lugar de destaque devido ao seu sabor e características diversas, mas para que seu cultivo seja viabilizado, faz-se necessário o desenvolvimento de sistemas de cultivo que contemplem desde a seleção de plantas matrizes e propagação ao plantio, tratos culturais e fitossanitários, colheita e pós-colheita. Muito pouco tem sido feito nesse sentido e a erosão genética da gabirobeira ocorre de forma acelerada notadamente no Centro-Oeste, onde as áreas de maior variabilidade são planas, de fácil mecanização e estão sendo ocupadas por grandes lavouras e pecuária intensivas, com tendência à integração de explorações, mas com a exclusão de toda biodiversidade autóctone (Vieira et al., 2010).
As mudas oriundas de sementes possuem a desvantagem de apresentar um longo período improdutivo, ocasionado pela fase de juvenilidade, somado à propriedade das sementes de perderem rapidamente o poder germinativo (Hartmann et al., 2011). Outro inconveniente a ser ressaltado é a grande variabilidade genética das sementes, o que resulta em plantas com diferenças acentuadas de vigor no campo e de qualidade dos frutos produzidos, reduzindo, assim, o interesse dos fruticultores, sendo que essas limitações podem ser minimizadas pela propagação clonal ou vegetativa (Lins et al., 2015).

Dentre as vantagens da propagação vegetativa, listam-se a manutenção das características genéticas das plantas-matrizes e a uniformidade e precocidade de produção. Entre as técnicas de propagação vegetativa destacam-se a estaquia, a alporquia e a enxertia (Hartmann et al., 2011).

A estaquia é um método de propagação vegetativa que consiste em destacar de uma planta matriz um órgão, ramo, folha ou raiz e colocá-los em meio adequado para enraizamento e desenvolvimento da parte aérea (Fachinello et al., 2011).

As auxinas são consideradas as principais substâncias promotoras do enraizamento adventício, principalmente para espécies que apresen-tam dificuldade em enraizar. Entre as auxinas sintéticas, o ácido indolbutírico (AIB) apresenta como vantagens a menor mobilidade e maior estabilidade química quando comparado ao ácido indolbutírico (AIA), além de ser menos fitotóxico que o ácido naftaleno acético (ANA) (Fachinello et al., 2011). 
A produção de mudas frutíferas por meio da estaquia é um método amplamente empregado, com algumas vantagens em relação aos demais métodos de propagação, tais como a facilidade de realização, baixo custo, rapidez na produção da muda e obtenção de descendentes com as mesmas características da planta matriz (Mindêllo Neto et al., 2008). No entanto, o uso da estaquia para a propagação da gabirobeira no Brasil é limitado pela falta de tecnologia eficiente e segura, justificando a necessidade de trabalhos científicos. Desta forma, o objetivo deste trabalho foi avaliar a aplicação de diferentes doses de ácido indolbutírico na propagação de gabirobeira.

\section{MATERIAL E MÉTODOS}

Em 10 de maio de 2016 foram coletadas estacas lenhosas de gabirobeiras da coleção do banco de germoplasma de Campomanesia spp. da UFG-Regional Jataí, em Jataí-GO. Utilizaram-se estacas das espécie Campomanesia adamantium e Campomanesia pubescens em dois experimentos. Após a coleta, as estacas foram acondicionadas em baldes contendo água e levadas para Casa de Vegetação da Regional Jataí. Em seguida, as estacas foram segmentadas em ramos $15 \mathrm{~cm}$ de comprimento contendo um par de folhas na parte apical e selecionadas as estacas que apresentavam diâmetro médio de 2,86 $\pm 1,29 \mathrm{~cm}$. Foi feito acompanhamento da temperatura do substrato, Casa de Vegetação e das folhas das estacas durante todo o período experimental (Tabela 1), com auxílio de termômetro infravermelho InfraRed Thermometer - ICEL TD 961.

O experimento foi conduzido em delineamento inteiramente casualizado para cada espécie em estudo com 5 tratamentos e 4 repetições com 8 estacas/parcela. Os tratamentos foram compostos por $0,800,1600,2400$ e $3200 \mathrm{mg} / \mathrm{L}$ de Ácido indolbutírico (AIB). A s estacas foram tratadas nas doses de Ácido indolbutírico (AIB), com 15 segundos de imersão.

Tabela 1 - Dados médios da temperatura $\left({ }^{\circ} \mathrm{C}\right)$ do substrato, casa de vegetação e das folhas das estacas de gabiroba. Jataí-GO, 2016

\begin{tabular}{lccc}
\hline & Substrato $^{(1)}$ & Casa de vegetação & Folha \\
\hline Média & 20,95 & 22,36 & 20,99 \\
Maior & 35,1 & 46,2 & 35,9 \\
Menor & 8,8 & 10,5 & 9,9 \\
Desvio & 6,43 & 7,02 & 6,25 \\
\hline
\end{tabular}

Após tratamento com AIB as estacas foram plantadas em bandejas de isopor ( $66 \times 34 \times 6 \mathrm{~cm})$, com as bases perfuradas com 128 células contendo como substrato areia lavada. Durante todo o período experimental foi utilizado o sistema de nebulização intermitente, programado para ser acionado por 10 minutos, em intervalos de oito minutos, o que permitiu a manutenção de umidade constante sobre a superfície das folhas.

Em 16 de maio foi feita uma adubação com 5\% do adubo foliar Niphokam (10-08-08). Em 02 de junho de 2016 e em 23 de junho de 2016 foi feita adubação com $20 \%$ de nitrogênio, utilizando-se como fonte de nitrogênio o sulfato de amônia, apresentando formulação com $20 \%$ de nitrogênio $\left(\mathrm{NH}_{4} \mathrm{SO}_{4}\right)$ e $24 \%$ de enxofre.

Sessenta dias após a instalação do experimento as estacas foram avaliadas, quanto a Brotação (número de estacas que emitiram brotos, sendo considerado broto a parte visível das estacas em estágios iniciais de desenvolvimento, no geral, consistindo folhas em desenvolvimento), sobrevivência das estacas (número de estacas vivas), porcentagem de enraizamento (a determinação da porcentagem de enraizamento foi feita a partir da contagem do total das estacas enraizadas em cada espécie), porcentagem de calejamento (a porcentagem de calejamento foi obtida a partir da contagem do número total de estacas com calos em cada espécie).

Os dados obtidos em função das doses de AIB foram submetidos à análise de variância e de regressão, com F $(p<0,5)$. Para explicar fisiologicamente o comportamento das plantas utilizaram-se modelos de regressões, sendo a escolha dos modelos baseada no coeficiente de determinação e no potencial para explicar o fenômeno biológico. Os dados foram analisados no programa estatístico Sistema de Análises Estatísticas e Genéticas da Universidade Federal de Viçosa, versão 9.1 (SAEG, 2009).

\section{RESULTADOS E DISCUSSÃO}

Para número de brotações de Campomanesia adamantium os dados foram ajustados com modelo quadrático (Figura 1A). Observa-se que a dose foi diretamente proporcional ao número de brotações, ou seja, à medida que se aumentou as doses aumentou o número de brotações até a dose $2400 \mathrm{mg} . \mathrm{L}^{-1}$, com decréscimo no número de brotações na dose de $3200 \mathrm{mg} . \mathrm{L}^{-1}$. Estes resultados 

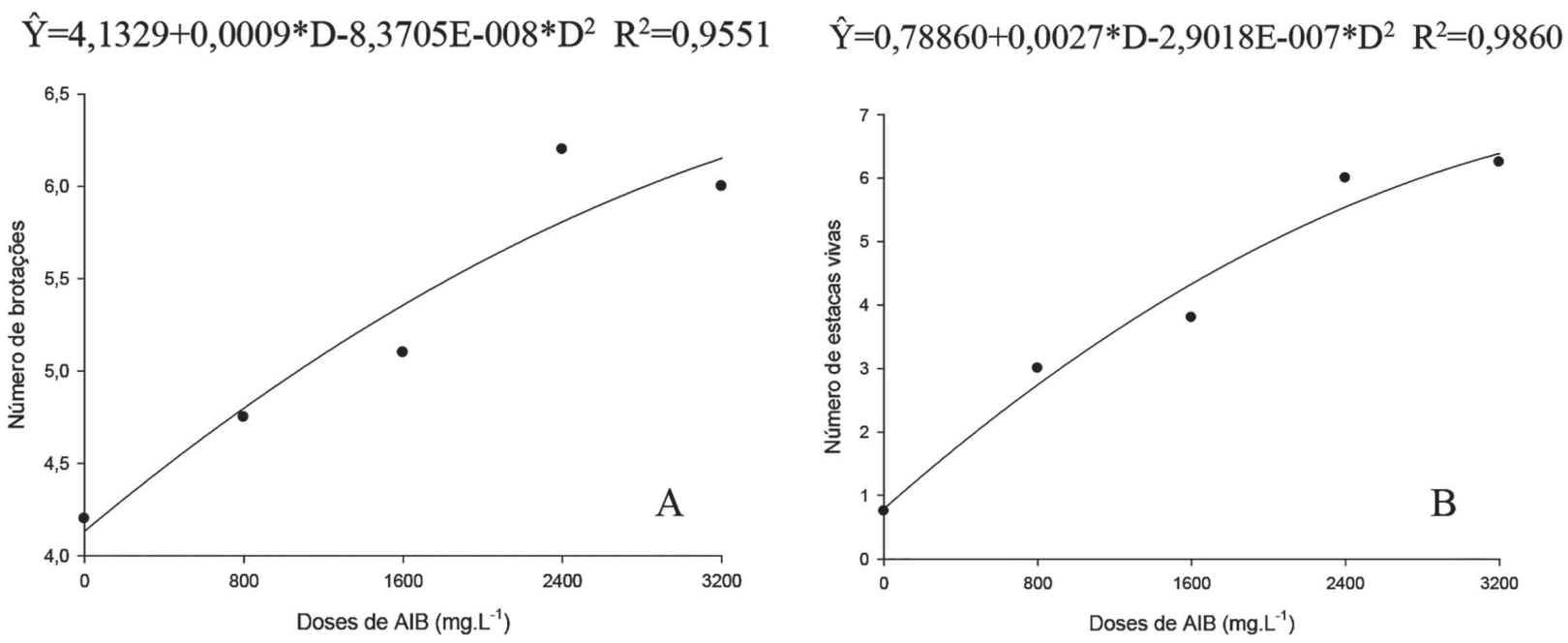

Figura 1 - A: Estimativa do número de brotações e B: Estimativa do número de estacas vivas de Campomanesia adamantium em função de doses de AIB (D).

demonstram a necessidade de testar doses maiores de AIB para a espécie em estudo

O número de brotações possivelmente relacionase com fatores endógenos, como os conteúdos de açúcares, sacarose, amido, ácido indolacético, ácido abscísico, sólidos solúveis totais e elementos minerais, os quais são variáveis ao longo do ano (Tsipouridis et al., 2006). Entre os fatores endógenos, as auxinas desempenham importante papel na brotação de estacas de diversas fruteiras e conforme pode ser observado neste trabalho, influencia na brotação de estacas de gabirobeira.

Para número de estacas vivas de Campomanesia adamantium os dados foram ajustados com modelo quadrático (Figura 1B). A porcentagem de estacas vivas foi de 9,$86 ; 34,5 ; 54,5 ; 69,96$ e $80,71 \%$ para as doses de $0,800,1600,2400$ e $3200 \mathrm{mg} / \mathrm{L}$, respectivamente. Indicando que quando maior a dose de AIB maior a porcentagem de estacas vivas.

Para número de brotações e número de estacas vivas em Campomanesia pubescens os dados foram ajustados com modelo quadrático (Figuras 2A e 2B).

A porcentagem de brotação foi de 47,$7 ; 60,7 ; 68,5$; 70,9 e $67,9 \%$ para as doses $0,800,1600,2400$ e 3200 $\mathrm{mg} / \mathrm{L}$, respectivamente. Através da derivada da equação observa-se o ponto de máximo para a dose $2766,1 \mathrm{mg} /$ $\mathrm{L}$, que proporcionou maior porcentagem de sobrevivência (Figuras 2A).
Para o número de estacas vivas, pela derivada da equação de regressão o ponto de máximo foi para a dose de $2385 \mathrm{mg} / \mathrm{L}$ de AIB, permitindo sobrevivência de $100 \%$ das estacas, indicando o potencial desta dose para esta característica (Figuras2B).

O número de brotações possivelmente relacionase com fatores endógenos, como os conteúdos de açúcares, sacarose, amido, ácido indolacético, ácido abscísico, sólidos solúveis totais e elementos minerais, os quais são variáveis ao longo do ano (Tsipouridis et al., 2006). Entre os fatores endógenos, as auxinas desempenham importante papel na brotação de estacas de diversas fruteiras e conforme pode ser observado neste trabalho, influencia na brotação de estacas de gabirobeira nas duas espécies do presente trabalho.

A sobrevivência de estacas de ramos é afetada por fatores externos, como a espécie, a concentração de ácido indolbutírico (AIB), a temperatura, luminosidade, substrato, a data de coleta dos ramos, a idade da planta matriz, e também pelo comprimento e o diâmetro das estacas (Timm et al., 2015).

A auxina é sintetizada nas gemas apicais e folhas novas, de onde é translocada para a base da planta por um mecanismo de transporte polar (Taiz \& Zeiger, 2013). O aumento da concentração de auxina exógena aplicada em estacas de gabirobeira permitiu maior sobrevivência das estacas, nas duas espécies em estudo. 

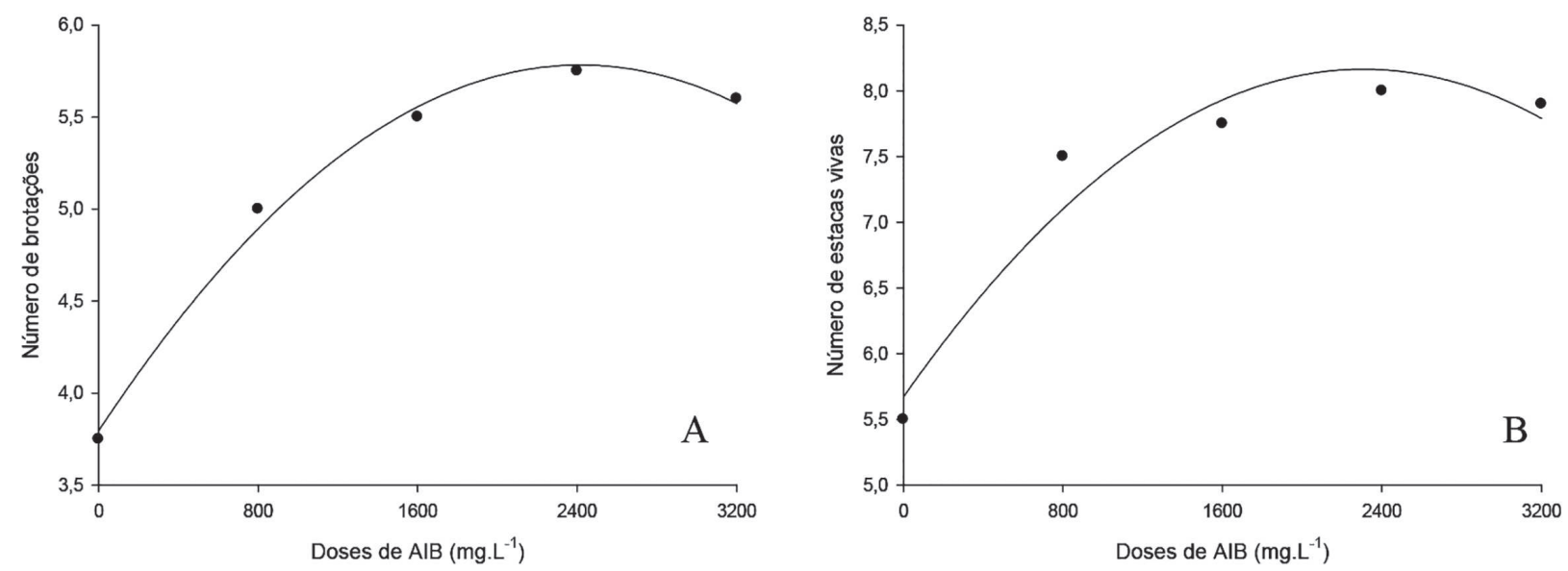

Figura 2 - A: Estimativa do número de brotações e B: Estimativa do número de estacas vivas de Campomanesia pubescens em função de doses de AIB (D).

Não foi observada formação de calo tanto para Campomanesia adamantium quanto para Campomanesia pubescens. Segundo Hartmann et al. (2011), a formação de calo é um precursor da formação de raízes adventícias em algumas espécies, mas na maioria das espécies são processos independentes, sendo a ocorrência simultânea devido à dependência de condições internas e ambientais semelhantes.

O uso de AIB não foi capaz de contornar o problema da limitada rizogênese em estacas de gabirobeiras, isto porque não foi observado enraizamento em nenhuma das espécies em estudo nas diferentes doses testadas de AIB. Observou-se que o uso da propagação via estaquia nas duas espécies de gabirobeiras associado ao uso de AIB não permitiu que os fotoassimilados e os reguladores de crescimento transportados pelo floema fossem retidos na região da estaquia e, assim, disponibilizados para indução radicular. Os fatores que afetam o enraizamento são classificados em internos ou endógenos, considerando, principalmente, as condições fisiológicas e a idade da planta matriz, o potencial genético de enraizamento, a sanidade e o balanço hormonal (Hartmann et al., 2011); e fatores externos ou exógenos, como a temperatura, a luz, a umidade e o substrato (Hartmann et al., 2002).

Lima et al. (2010), estudando o efeito de doses de AIB em diferentes substratos na propagação de Maytenus muelleri por alporquia, não obtiveram enraizamento para nenhum dos substratos avaliados, dentre eles a fibra de coco e o esfagno. Pode-se inferir, portanto, que espécies distintas apresentam diferentes respostas aos diferentes substratos, considerando que não há falhas de metodologia.

A formação da raiz adventícia é um processo complexo e dependente de fatores como o nível de fitorreguladores endógenos, presença de carboidratos, presença ou ausência de gemas dormentes e emergência de brotações (Smart et al., 2003). Segundo Hartmann et al. (2011), raízes adventícias em estacas de plantas com crescimento secundário se originam a partir do tecido jovem do floema secundário, dos raios vasculares, do câmbio ou dos calos produzidos na base das estacas.

Os carboidratos são fonte de carbono e de energia para a biossíntese de ácidos nucleicos e proteínas, além de outras substâncias essenciais à formação de raízes (Fachinello et al., 2005).

Segundo Hartmann et al. (2011), a divisão celular é favorecida pelo aumento da temperatura, consequentemente ela auxilia a formação de raízes e a produção de brotos. No presente trabalho, observouse índices elevados de formação de brotos para as duas espécies em estudo, todavia não houve enraizamento. O período de coleta das estacas foi no outono, estação na qual são registradas baixas temperaturas e baixa precipitação pluviométrica. De 
acordo com Hartmann et al. (2011), temperaturas baixas diminuem o metabolismo, levando à menor produção de brotações e ao maior tempo para o enraizamento, ou, até mesmo, não proporcionam condições adequadas para que ocorram indução, desenvolvimento e crescimento radicular. $\mathrm{O}$ que pode ser confirmado neste trabalho, onde não observou-se formação de calos e raízes.

De acordo com Hartmann et al. (2011), a época do ano é um fator importante que influencia o enraizamento das estacas, pois se relaciona diretamente com a condição fisiológica da planta-matriz e com suas fases de desenvolvimento, interferindo assim na produção de substâncias promotoras de crescimento. O período mais apropriado para a propagação vegetativa via estaquia para a maioria das fruteiras cultivadas é a partir da primavera até o final do verão, quando as funções metabólicas da planta se encontram em plena atividade, fazendo com que haja grande síntese e armazenamento de carboidratos, importantes na formação de raízes.

Devido às alterações metabólicas da planta induzidas pelas oscilações climáticas, é possível inferir que haja uma época do ano mais propícia à propagação da gabirobeira, quando se espera obter maior enraizamento nas mudas produzidas pela técnica da estaquia. Sendo assim, sugere-se que a coleta das estacas para propagação de gabirobeiras seja feita no período de primavera-verão.

Para ampliação tanto da produção como para incentivo de cultivo comercial, é necessário que haja estudos relacionados à produção de mudas com boa qualidade genética e fitossanitária, além de homogêneas, para facilitar o manejo do pomar. Portanto, a propagação conduzida na época do ano adequada, aliada à utilização de um bom substrato, pode otimizar a produção de mudas de gabirobeiras que assegurem a formação de pomares uniformes e altamente produtivos, cujos frutos apresentem padrões definidos, que possibilitem sua comercialização como fruta fresca.

Dessa forma, pode-se inferir que a realização da estaquia da gabirobeira no mês de maio representaria um gasto metabólico para a planta, já que não houve formação de raízes e nem formação de calos.

\section{CONCLUSÕES}

O uso de AIB em estacas de gabirobeiras na dose de $2766,1 \mathrm{mg} / \mathrm{L}$ proporcionou maior percentagem de brotação e a dose de $2385 \mathrm{mg} / \mathrm{L}$ maior sobrevivência das estacas, porém não proveu formação de calos e enraizamento.

\section{AGRADECIMENTOS}

Ao Programa de Pós-Graduação em Agronomia da Universidade Federal de Goiás (UFG- Regional Jataí), CAPES, CNPq e FAPEG pelo apoio financeiro.

\section{LITERATURA CITADA}

BRASIL. Novo código florestal. lei $\mathrm{n}^{\circ}$ 12.651, de 25 de maio de 2012. 2012. Disponível em: <http://sbcpd.org/portal/images/stories/NovoCodigo-Floresta-Lei-12651-2012.PDF> (acessado em 15 de junho de 2015).

BRASIL. LEI No 13.123, DE 20 DE

MAIO DE 2015. Disponível em <http:// www.planalto.gov.br/ccivil_03/_Ato2015-2018/2015/ Lei/L13123.htm> (acessado em 15 de junho de 2015).

FACHINELLO, J.C.; HOFFMANN, A.; NACHTIGAL, J.C. Propagação de plantas frutíferas. Brasília: Embrapa Informação Tecnológica, 2005. 221p.

FACHINELLO, J.C.; PASA, M.S.; SCHMTIZ, J.D.; BETEMPS, D. L. Situação e perspectivas da fruticultura de clima temperado no Brasil.

Revista Brasileira de Fruticultura, v. especial, p.109-120, 2011.

HARTMAnN, H.T.; KESTER, D.E. Plant propagation: principles and practices. $7 \mathrm{a}$. ed. New Jersey: Prentice-Hall, 2002, 880p.

HARTMANN, H.T.; KESTER, D.E.; DAVIES JUNIOR, F.T.; GENEVE, R.L. Plant propagation: principles and practices. 8.ed. New Jersey: Prentice Hall, 2011. 915p.

LIMA, D.M.; BIASI, L.A.; ZANETTE, F.; ZUFFELLATO-RIBAS, K.C. Alporquia em espinheira-santa. In: SEMINÁRIO DE SISTEMAS DE PRODUÇÃO AGROPECUÁRIA, 4., 2010, Dois Vizinhos. Anais... Dois Vizinhos, PR: UTFPR, 2010.

LINS, L.C.R.; SALOMÃO, L.C.C.; CECON, P.R.; SIQUEIRA, D.L. The lychee tree propagation by layering. Revista Brasileira de Fruticultura, v.37, p.480-487, 2015. 
MINDÊLLO NETTO, U.R.; TELLES, C.A.; BIASI, L.A. Enraizamento adventício de estacas semilenhosas de cultivares de pessegueiro.

Scientia Agraria, v.9, n.4, p.565-568, 2008.

SAEG. Sistema para análises estatísticas, versão 9.1: Fundação Arthur Bernardes, UFV, Viçosa, MG, 2009.

SMART, D.R.; KOCSIS, L.; WALKER, M.A.; STOCKERT, C. Dormant buds and adventitious root formation by Vitis and other woody plants. Journal of Plant Growth Regulation, v.21, p.296314, 2003.

TAIZ, L.; ZEIGER, E. Fisiologia vegetal. 5. ed. Porto Alegre: Artmed, 2013. 954p.
TIMM, C.R.F.; SCHUCH, M.W.; TOMAZ, Z.F.P.; MAYER, N.A. Enraizamento de miniestacas herbáceas de porta-enxertos de pessegueiro sob efeito de ácido indolbutírico. Semina, v.36, n.1, p.135, 2015.

TSIPOURIDIS, C.; THOMIDIS, T.; MICHAILIDES, $Z$. Influence of some external factors on the rooting of GF677, peach and nectarine shoot hardwood cuttings. Australian Journal of Experimental Agriculture, v. 45, n. 1, p. 107-113, 2006.

VIEIRA, R.F.; AGOSTINI-COSTA, T.S.; SILVA, D.B.; SANO, S.M.; FERREIRA, F.R. Frutas Nativas da Região Centro-Oeste do Brasil. Brasília: Embrapa Informação Tecnológica, 2010. 322p.

Recebido para publicação em 28/9/2016 e aprovado em 14/3/2017. 